\title{
The Social and Economic Effects of Deterioration in Health: 'Naked-eye' Evidence from a European Panel Survey
}

\author{
Antigone Lyberaki and Platon Tinios
}

\section{A Naked-Eye Approach to the Mobilization of Societal Reserves}

S ocial solidarity and cohesion are often extolled and frequently theorized. Especially in times of hardship the mechanisms of social solidarity by providing help where that is needed comprise the social safety net. Much of the literature comparing and contrasting the European and US experiences of growth models lay stress on the key importance of European Social safety nets as a factor differentiating Europe and explaining some of the salient differences.' Similarly, within Europe, important streams of literature concern themselves with providing typologies of Welfare states and systems.

To complement this theoretical difference it is important to see the mobilization of social reserves in action as applied to individuals. To examine, in other words, concrete cases where social support systems are called to serve an apparent and indisputable need. This paper examines one particular class of such events, where a clear instance of need arises, in order to discern what responses are called forth. The same event is examined in a random sample of cases across Europe in order to try to discern patterns of similarity and difference of response in different institutional (and national settings). The case of 'need' examined is that of the onset of sudden and serious illness in older individuals (between 50 and 80) across Europe. Such cases would certainly fulfil any definitions of 'deserving need', while the fact that information is available on specific individuals identified to have suffered serious deterioration in their health status between the two waves of panel survey allows us to correlate responses and consequences in a systematic manner. In doing so, it is

1 Alber, 2006; Boeri, 2002; CEC, 2002; Sapir, 2005.

2 Esping-Andersen, 1990, 1996; Ferrera, 1996. 
possible to see how responses in different social protection systems would differ in practice.

The social protection systems identified in the literature ${ }^{3}$ are the Anglo-Saxon, the Nordic and the Continental. Ferrera (1996) further distinguishes the Mediterranean as a distinct category within the conservative typology.

To approach this rather complex issue is certainly an ambitious undertaking, and exploits the availability of individual data from the European panel survey of persons aged 50+. The Survey of Health and Retirement in Europe (SHARE) ${ }^{4}$ allows us to begin an approach towards this undertaking. The SHARE data combines four qualities that, uniquely, allow an explicit consideration of many questions.

1. It contains data referring to individuals. Working at the level of the individual, we are able to pick out social support responses of an informal nature which are seldom captured in macro, system-wide data. SHARE has data for 30 thousand individuals spread out over 12 countries (in the first wave $)^{5}$.

2. There is an explicit time dimension. The data set is a panel, i.e. the same individuals were interviewed in 2004 and again in 2007/8). This allows the identification of cases where an illness or health condition first appeared in 2007 -i.e. to spot cases of the onset of health problems. In such cases it is possible to disentangle the before and after of the illness, to separate cause from effect.

3. The questionnaire is multidisciplinary in construction. Given that responses to illness will call forth reserves and have consequences on the family, society and economy, data must be open to insights from the disciplines of medicine, economics, sociology, psychology. Indeed the SHARE questionnaire was fashioned as multidisciplinary exercise with this necessity in mind.

3 Such as in the work of Esping-Andersen, 1990, 1996.

4 SHARE offers a valuable source of information on economic, health and social issues while allowing international comparisons on the basis of a common interview material covering 30,000 individuals aged over 50 in 11 European countries (Börsch-Supan et al., 2005, www.shareproject.org). The SHARE data collection has been primarily funded by the European Commission through the 5th framework programme (project QLK6-CT-2001- 00360 in the thematic programme Quality of Life) and through the 6th framework programme (projects SHARE-I3, RII-CT- 2006-062193, and COMPARE, CIT5-CT-2005-028857). Additional funding came from the U.S. National Institute on Aging (U01 AG09740-13S2, P01 AG005842, P01 AG08291, P30 AG12815, Y1-AG-4553-01 and OGHA 04-064, IAG BSR06-11, OGHA04064).

5 In the second wave further data have been collected in Czech Republic, Poland as well as Ireland. The third wave will collect data in sixteen countries in 2008-2009 (Börsch-Supan et al., 2008). 
4. There must be comparability across countries. This comparability goes beyond a consistent translation of the language of the questionnaire and proceeds to comparability of concepts. Indeed international comparability was one of the key concerns of SHARE from the outset. The wide international dispersion allows consideration of Mediterranean countries (Spain, Italy and Greece), Continental European countries relying on social insurance (Austria, Germany, Belgium, France and Switzerland) and Nordic (Sweden and Denmark). Given the similarity in social protection system the Netherlands is included (for the purposes of this paper) in the Nordic group.

This paper first identifies the cases of direct health deterioration between the two waves of SHARE in all 11 countries that have data for both waves. In doing so a tradeoff must be struck between similarity (and seriousness) of condition and sample size. A group of 2 thousand individuals spread equally across the three welfare state regimes between 50 and 80 who have seen deterioration in their health is thus identified; this identification of this group allows the analysis to proceed.

Having identified a group the analysis of this paper, proceeds by an impressionistic approach, relying on descriptive statistics and simple comparisons to identify general areas of similarity and/ or difference. The object of this 'enterprise' is to give an overview and brief characterization of the problems faced by different individuals in different parts of Europe when confronted by similar problems. Such a naked eye' approach should pick up major effects and, by spreading the net widely and impressionistically, could identify large cross-cutting effects. It is thus left for subsequent more focused analyses to probe further by isolating specific areas and examining particular hypotheses in depth.

The analysis then proceeds by examining direct health consequences - physical deterioration most obviously but also mental health. The contacts with the health system are then examined both in terms of frequency and of out-of-pocket expenses. Implications outside the health area are the subject of the last two sections: labour force participation is a very live issue for the group 50-64 who are on the threshold of retirement anyway.

The area of social consequences is touched upon by seeing whether health deterioration can call forth a response in informal care received from outside the household. The tentative conclusions bring to a close the naked-eye analysis by suggesting avenues of further study.

6 SHARE was consciously designed to be comparable with the Health Retirement Survey (HRS) of the US and the English Longitudinal Study on Ageing (ELSA) (Börsch-Supan and Jürges, 2005; Meijer et al., 2008) 
This kind of evidence documents the contact of a random sample of the population with the health system in a wide selection of health care (and social policy environments), faced with similar challenges. This contemporary evidence may be thought to encapsulate the integral of key policy and social changes taken over long periods as they impinge on individuals over 50 years of age. It thus, by providing illustrations of actual operation of health systems on a controlled sample of the population, it may aid understanding of health systems themselves.

\section{Identifying Health Deterioration}

The object of the analysis is to identify a group in the SHARE longitudinal sample who, between the first and second wave of the study, have obviously suffered a sudden and serious health deterioration that disturbs programs and forces changes in the rhythms of daily life. It was thus decided to limit our attention to individuals younger than 80 years of age; over 80 years health deterioration is much more common and hence, one would presume, anticipated. The lifestyles of respondents of individuals $80+$ are already geared to the anticipation of health deterioration and thus the onset of illness can be expected to lead to different effects. Moreover, the possibility of returning to the pre-deterioration physical, social and economic situation is presumably very different for the over- and under-80s. Similarly, the event of a death between the first and second wave has important effects on those left behind, which however can be expected to be different than an illness ${ }^{7}$. For some analysis though the effect of illness on the life and decisions of the (healthy) spouse is examined separately.

The definition of health deterioration has to walk a tightrope: on the one hand the health conditions should be, as far as possible, similar in their wider economic and social implication, which implies a threshold of 'seriousness' and possibly a grouping of similar conditions. Moreover, they would have to satisfy the criterion of 'suddenness' - i.e. it should be something that did not exist in the first wave. On the other hand, and crucially, one must be mindful of securing sample sizes that allow statistical inference to proceed. Given that the group of 50-80 year-olds contains two separate subgroups: (a) People aged 50-65 for whom participation in employment or gainful activity if not a reality is at least a live option. (b) Those aged $65+$ who have mostly severed their links with the labour market.

7 In the case of death in the SHARE sample, the deceased's family or other informed persons are asked to complete an 'Exit interview'. 
The definition finally settled on relies on a combination of observed major illness and deterioration in self-perceived health. Thus the selecting algorithm selects an individual as having suffered health deterioration if:

- Either he/she declares in the second wave that he/she suffered any of 4 illnesses between 2004 and 2006/7: Heart attack, Stroke, Cancer, Hip fracture.

- Or, he/she experienced deterioration in rating of Self-Perceived Health (SPH): All those whose estimation of their status changed to "Poor" or whose SPH was reduced by more than two scales.

Thus in the question that asked interviewees about their current health status, the possible answers range from: "excellent", "very good", "good", "fair" and "poor" according to the self-perceived health based on US version (SPHUS). Using this information for wave 1 and wave 2, we define deterioration in health status if:

- a person was in excellent health in wave 1 and now is in fair health status (3 scales)

- a person was in excellent health in w1 and now is in poor health status (-4 scales)

- a person was in very good health in 1 and now is in fair health status $(-2$ scales)

- a person was in very good health in $\mathrm{w} 1$ and now is in poor health status (-3 scales)

- a person was in fair health in $\mathrm{w} 1$ and now is in poor health status (-1 scales for those already in less than good health).

Finally, in order to maximize sample sizes it was decided to segment the sample not by country but instead to group countries according to typology of welfare states. Thus all results are reported in terms of "Nordic countries" (Sweden, Denmark, Netherlands), "Continental countries" (Germany, Belgium, France, Austria, Switzerland) and "Southern countries" (Spain, Italy, Greece). This typology apart from geographical criteria and characteristics of the social protection systems ${ }^{8}$ can be further justified with two arguments: First, significant differences are known to exist across European countries regarding institutional care and home help services targeted to elderly persons. For instance, Bettio and Plantenga (2004: 98-99) document that the Mediterranean countries exhibit the lowest rates of residential and community services for the elderly people, while, on the other hand, the Nordic countries (Denmark, Netherlands and Sweden) are represented among the

8 Esping-Andersen, 1990, 1996; Ferrera, 1996; Sapir, 2005. 
Table 1. Application of the Health deterioration algorithm to the SHARE longitudinal 50-80 years of age sample (number of cases).

\begin{tabular}{|c|c|c|c|c|c|c|c|}
\hline \multirow{2}{*}{$\begin{array}{c}\text { SHARE } \\
50-80\end{array}$} & \multirow{2}{*}{$\begin{array}{c}\text { Self- } \\
\text { perceived } \\
\text { deterio- } \\
\text { ration } \\
\end{array}$} & \multicolumn{4}{|c|}{ Identified health events } & \multirow{2}{*}{$\begin{array}{l}\text { Any of } \\
\text { the four } \\
\text { chronic } \\
\text { diseases }\end{array}$} & \multirow{2}{*}{$\begin{array}{c}\text { Total } \\
\text { Health } \\
\text { deterio- } \\
\text { ration } \\
\end{array}$} \\
\hline & & $\begin{array}{l}\text { Heart } \\
\text { attack }\end{array}$ & Stroke & Cancer & $\begin{array}{c}\text { Hip } \\
\text { Fracture }\end{array}$ & & \\
\hline Nordics & 337 & 178 & 60 & 107 & 41 & 364 & 624 \\
\hline Continental & 493 & 292 & 98 & 109 & 57 & 556 & 899 \\
\hline Southern & 396 & 150 & 54 & 43 & 32 & 269 & 593 \\
\hline All countries & 1226 & 620 & 212 & 259 & 130 & 1189 & 2116 \\
\hline
\end{tabular}

Source: SHARE (Survey on Health, Ageing and Retirement in Europe), wave 1 (2004) and wave 2 (2008)

top four providers regarding these services. Second, observed differences across European countries regarding family ties, ${ }^{9}$ family support, ${ }^{10}$ as well as labour force participation of the elderly. ${ }^{11}$ Hence, disaggregating by country groups (Nordics; Continental and Southern) allows for depicting potentially differential effects of the dynamic changes of these parameters on health outcomes across country groups.

Table 1 gives the sample sizes and an impression of how the selection algorithm operates.

Given that the analysis is based on re-interviews, it is likely to be sensitive to different average lengths of time intervening between the two waves. In particular, if the gap between waves is longer in some cases rather than in others, that is likely to be reflected in a greater (apparent) probability of health deterioration. Table A1 in the appendix provides information on the distribution of gaps by country, country grouping and health category. Gaps are notably short in France and Belgium; however little systematic difference is apparent by health status. The distributions may back the argument that the probable gain in explicitly correcting for differential time gaps does not outweigh the loss in simplicity of exposition. As a result, though this caveat must be borne in mind, no correction for this feature was attempted.

The total longitudinal sample in SHARE is 18741 individuals in 11 countries. Those aged between 50 and 80 years are 16807 individuals. The total number picked out by the algorithm is 2116 individuals, or $12.6 \%$ of the sample. This sample is split more or less evenly in each of the three country groupings. Slightly more than half of the sample is selected for having suffered one of the four identified health events: The largest group is heart attack (620) followed by Cancer (259), Stroke (212) and Hip fracture (130). The balance of slightly under one thousand

9 Reher, 1998; Kohli et al., 2005.

10 Attias-Donfut et al., 2005.

11 Brugiavini et al., 2005. 
individuals are picked out because of a declared deterioration in self-perceived health. This could be due to the onset of a condition not specified explicitly, or because of a general sense of not being well. Finally for some analyses, the group whose spouse suffered a health deterioration but are themselves healthy were also identified (7.5\% of the sample of 50-80 who live with a spouse or 972 individuals).

Figure 1 examines the prevalence of serious health deterioration by gender, age and country group. The headline that could be attached to the figures could be 'Disease does not discriminate': As one would expect the prevalence of deterioration is larger for the older group 65-80 by 6-7 percentage points. Prevalence hardly differs by gender or by country group. There is a 1-point greater prevalence for younger men, which disappears for the older group. It is worth mentioning that the difference in the prevalence of health deterioration between males and females appears to be statistically significant at a conventional level (P-value 0.0535$)$ only for persons aged 65-80 years in Southern Europe. The one anomaly concerns the older age group for women in Southern countries: The prevalence of deterioration is more than twice as high (11 points) than those of younger women in the same countries and some 4.3 points higher than men of the same category. It is interesting to note, further that this anomaly is caused by self-perceived health deterioration rather than the identified illnesses (where prevalence is similar to that pertaining for the same group in other countries).

Figure 1. Prevalence of health deterioration by gender, age and country group.

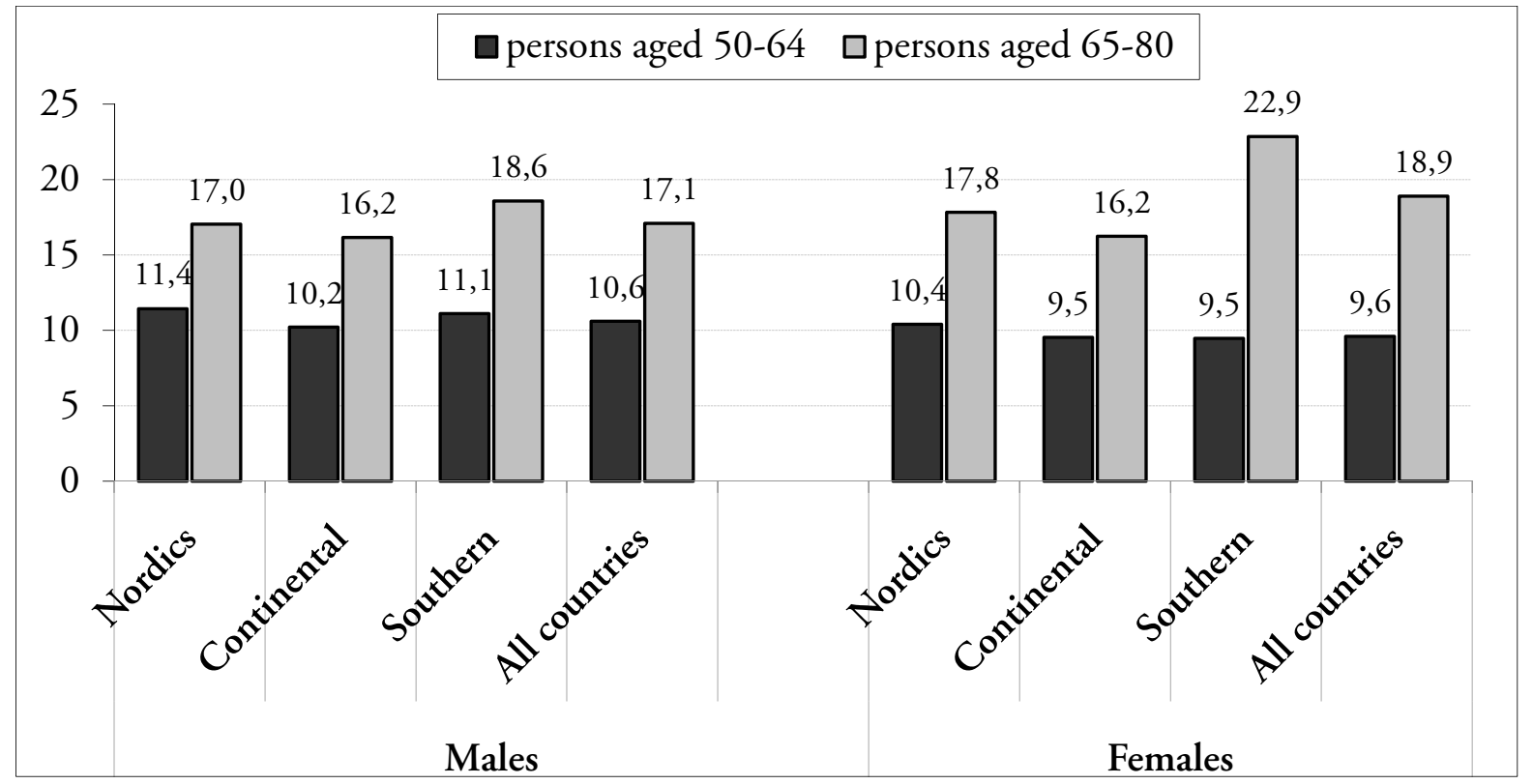

Source: SHARE, wave 1 (2004) and wave 2 (2008). 


\section{Immediate Effects of Deterioration in Daily Life}

The immediate and most proximate effects of health deterioration can be expected to be seen in physical measures of the ability to function. We utilize three of the direct measurements of physical condition that SHARE contains:

- The extent to which the ability to perform simple 'Activities of Daily Living' (ADL) are impaired. The question on ADLs is a well-known and well-understood question in health condition survey (Avendano and Mackenbach, 2008; Mackenbach et al., 2005). It asks respondents if they had difficulty performing a number of simple everyday activities on their own (e.g. a) Dressing; b) Walking across a room; c) Bathing or showering; d) Eating; e) Getting in and out of bed; $\mathbf{f}$ ) Using the toilet). This measure can be scored from 0 to 6 , depending on the number of ADL activities the respondent is unable to perform.

- Similar in nature is the Instrumental Activities of Daily Living (IADL), which asks respondents whether they are able to perform tasks needed to function in society on their own (e.g. a) Using a map to figure out how to get around in a strange place; b) Preparing a hot meal; c) Shopping for groceries; d) Making telephone calls; e) Taking medications; f) Doing work around the house or garden; g) Managing money). This measure varies from 0 to 7 depending on the number of IADL activities the respondent is unable to perform.

- Finally limitations in functioning are measured by self-reports on mobility (Nicholas et al., 2003). A question is asked on mobility due to a health or physical problem covering activities as (a) walking 100 meters; b) sitting for about 2 hours; c) getting up from a chair after sitting for long periods; $\mathbf{d}$ ) climbing several flights of stairs without resting; e) climbing one flight of stairs without resting; f) stooping kneeling or crouching; g) extending your arms above shoulder; $\mathbf{h}$ ) pulling or pushing large objects; $\mathbf{j}$ ) carrying weights over 5 kilos; $\mathbf{k}$ ) picking up a small coin from a table). This measure varies from 0 to 10 .

Table 2 tries to track physical deterioration on ability to function. The percentage of respondents reporting a deterioration of at least $1 \mathrm{ADL}, 1 \mathrm{IADL}$ or 1 on the mobility score is reported. Given that our sample is composed of older individuals and that the passage of 2-3 can be expected to worsen these scores in any case, the corresponding percentages for those not reporting health deterioration are also included. Finally, odds ratios are calculated (the number of times the probability of the deterioration group exceeds those not reporting deterioration).

As expected, Table 2 is unequivocal that health deterioration leads to major physical handicaps that impair the ability to live normally, at least as that is 
Table 2. Effects of health deterioration on ability to function, (\% reporting deterioration in measure and odds ratios by health deterioration status).

\begin{tabular}{|c|c|c|c|c|c|c|c|}
\hline \multirow[t]{2}{*}{ Age } & \multirow{2}{*}{$\begin{array}{l}\text { Change in } \\
\text { health }\end{array}$} & \multicolumn{2}{|c|}{$\begin{array}{c}+1 \text { OR MORE } \\
\text { ADL }\end{array}$} & \multicolumn{2}{|c|}{ +1 OR MORE IADL } & \multicolumn{2}{|c|}{$\begin{array}{c}\text { +1 OR MORE } \\
\text { MOBILITY }\end{array}$} \\
\hline & & Males & Females & Males & Females & Males & Females \\
\hline \multirow{3}{*}{$50-64$} & No deterioration & 2.5 & 3 & 4.3 & 5.8 & 3.5 & 3.4 \\
\hline & Deterioration & 7.6 & 9.7 & 10.1 & 16.8 & 7.9 & 9.2 \\
\hline & Odds ratio & 3.04 & 3.23 & 2.35 & 2.90 & 2.26 & 2.71 \\
\hline \multirow{3}{*}{$65-80$} & No deterioration & 4.9 & 6.9 & 7 & 11.9 & 5.7 & 4.9 \\
\hline & Deterioration & 19 & 23.1 & 25.3 & 36 & 18.3 & 20.2 \\
\hline & Odds ratio & 3.88 & 3.35 & 3.61 & 3.03 & 3.21 & 4.12 \\
\hline \multirow{3}{*}{$50-80$} & No deterioration & 3.60 & 4.8 & 5.5 & 8.7 & 4.5 & 4.1 \\
\hline & Deterioration & 14.2 & 18.5 & 18.9 & 29.4 & 14 & 16.5 \\
\hline & Odds ratio & 3.94 & 3.85 & 3.44 & 3.38 & 3.11 & 4.02 \\
\hline
\end{tabular}

Source: SHARE, wave 1 (2004) and wave 2 (2008).

measured by being able to perform simple tasks. In all cases the probability of ability to deterioration is some 3 or more times greater than of individuals with the same age and sex. It appears that the deterioration is felt sharper by men rather than by women: All odds ratios when comparing the younger with the older age group rise faster for men than for women. In the case of men the odds ratio rises from $3.04(50-65)$ to 3.88 (65-80); for women the increase is more moderate (3.23 to 3.35), a pattern which is repeated in IADLs, though not for mobility where (presumably due to obesity problems), the effect on mobility is much larger. A further point to note, which is somewhat obscured by the odds ratios, is that the extent of problems in daily functioning and their link with age is large even in the group not suffering for health deterioration.

Looking at this issue in greater detail, Figures $2 \mathrm{a}, 2 \mathrm{~b}$ and $2 \mathrm{c}$ examine odds ratios by age, gender and country group. It appears that the South feels the effects more keenly, in the sense that odds ratios of reporting functioning impairment as a result of illness are consistently higher there as compared to other areas by gender. Odds ratios are larger by over 0.7 , and more so for women. The special feature affecting mobility and older women is confirmed, and is shown to affect especially women from the north and centre of Europe, rather than the south. 
Figure 2a. Odds ratios for ADL deterioration by country group and gender.

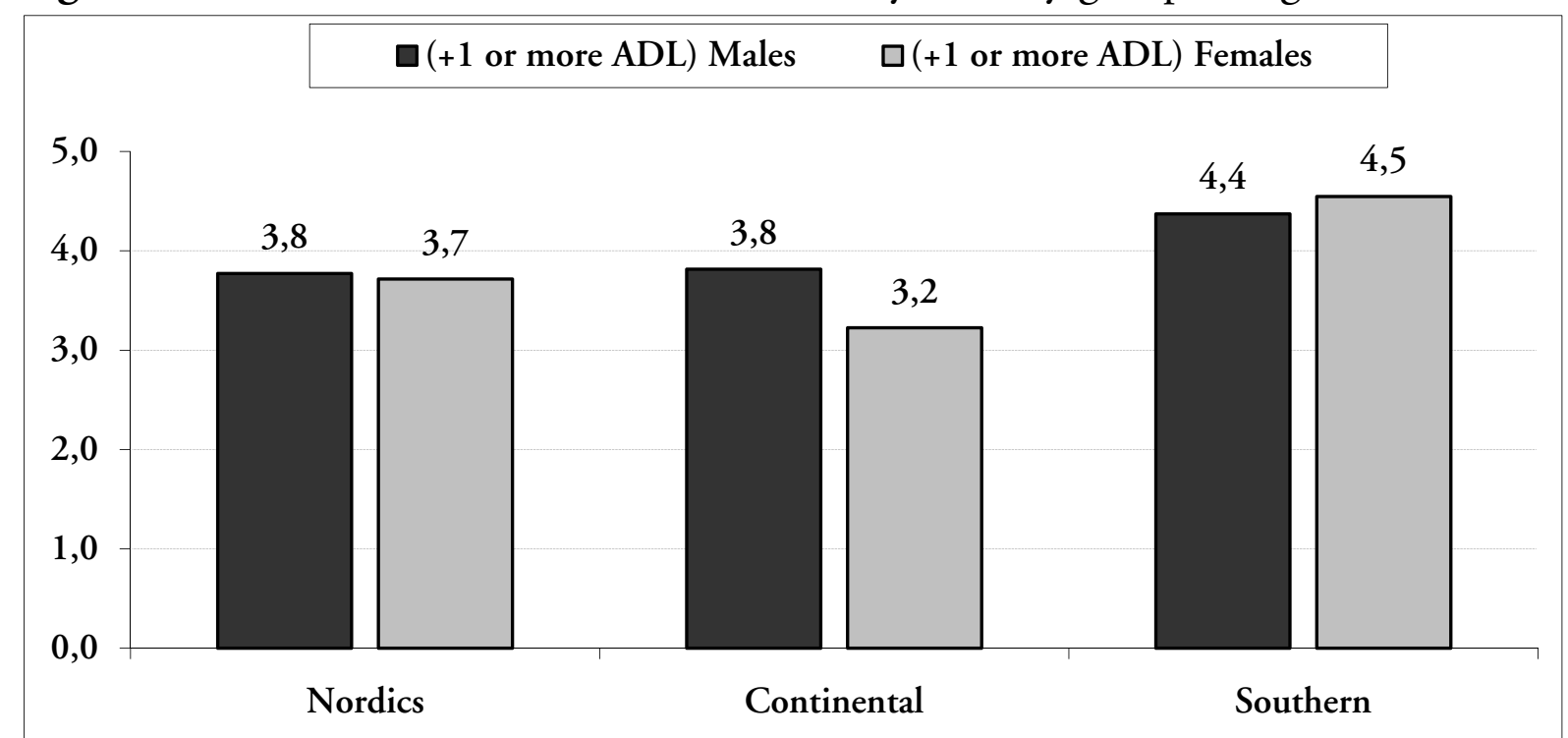

Source: SHARE, wave 1 (2004) and wave 2 (2008)

Figure $2 \mathbf{b}$. Odds ratios for IADL deterioration by country group and gender.

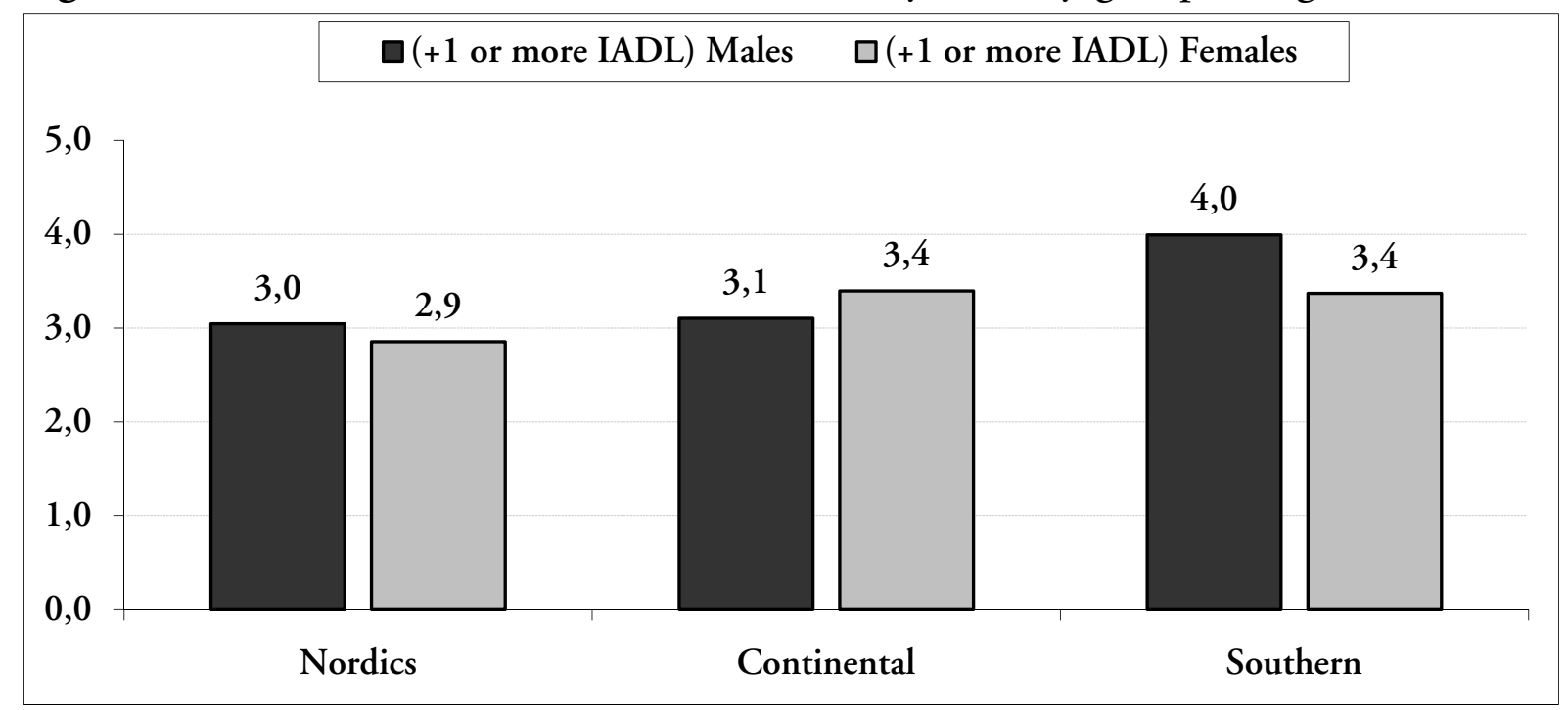

Source: SHARE, wave 1 (2004) and wave 2 (2008).

Illness and deterioration in health in addition to physical must be expected to have psychological and mental effects. Depression prevalence is measured in SHARE by the EURO-D scale a 12 point scale designed to spot the cases where replies indicate the presence of (possibly untreated) clinical depression (Prince et al., 1999a; 1999b). Figure 3 reports odds ratios of reporting a EURO-D score of greater than 3, a level which is conventionally taken to indicate the prevalence of possibly clinical depression (Dewey and Prince, 2005) by age, country grouping and separately by gender. 
Figure 2c. Odds ratios for mobility deterioration by country group and gender.

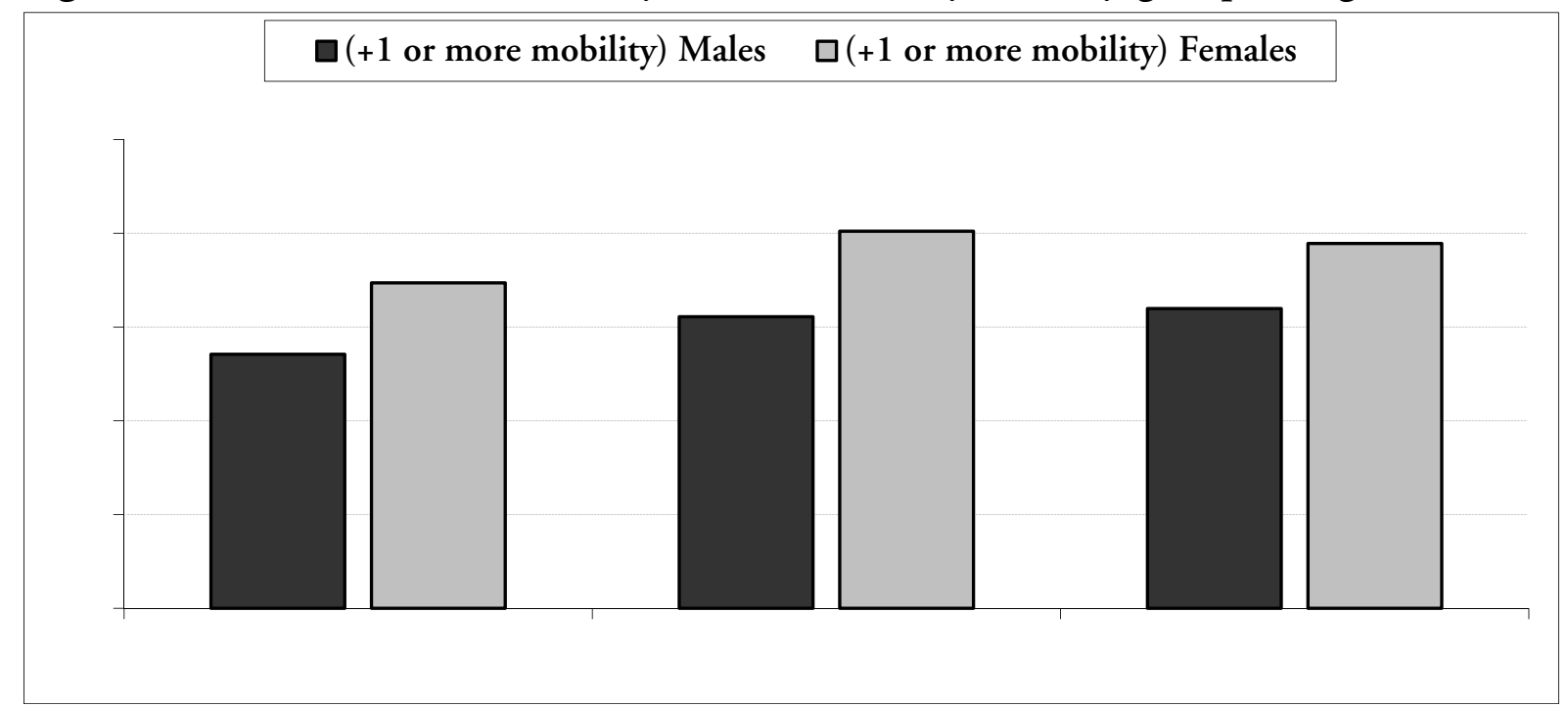

Source: SHARE, wave 1 (2004) and wave 2 (2008).

Figure 3. Prevalence of clinical depression (odds ratios) by age, area and gender.

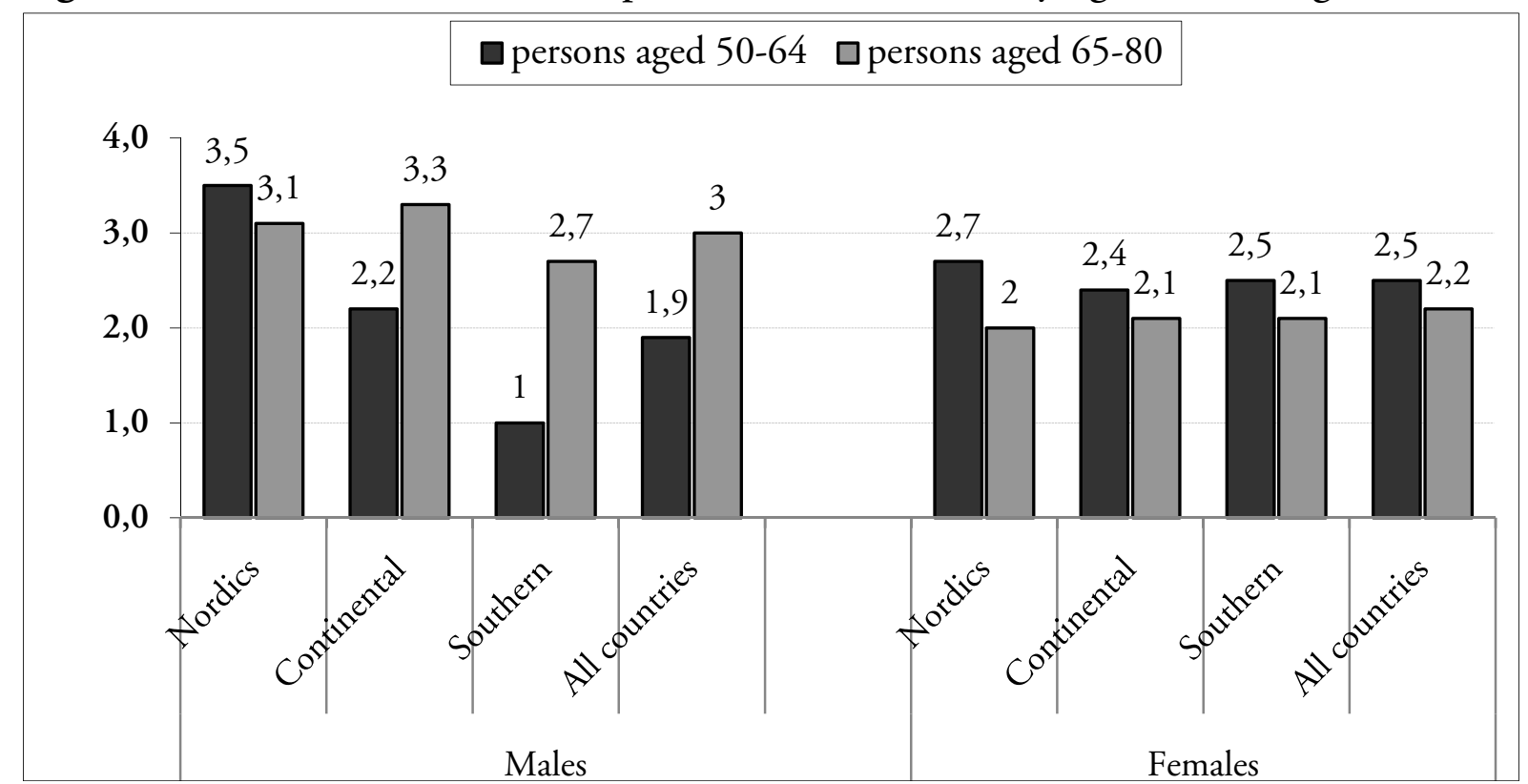

Source: SHARE, wave 1 (2004) and wave 2 (2008).

Figure 3 shows an interesting, if complex, picture. Women are anyway more prone to depression than men: the $\%$ of EURO-D $>3$ in the 'healthy' (non-deteriorating) group is $6.7 \%$ for men and 10.2 for women. However, the onset of illness appears to be felt more dramatically by men, especially as age progresses. Thus while men exhibit a steep age gradient (with the possible exception of the North), in all cases age gradients for women appear to be falling with age. An interpretation that could be offered is that men see illness as a very important indicator of advancing age and hence of mortality; women all across the sample appear to be taking a much more philosophical view and are not reacting as violently as men when illness strikes. 
Indeed, the picture of Figure 3 shows rather that women are increasingly coming to terms with impending mortality.

\section{Contacts with the Health Care System}

The first call, when illness strikes, is made to the health care system. Figures $4 \mathrm{a}$ and $4 \mathrm{~b}$ examine the number of visits to the doctor and the percentage who stayed in hospital over the last 12 months, respectively. For some this period would cover the period of their illness itself, while for others it might represent the aftermath of the disease. What is most readily apparent in the data of the two parts of the figure is the variety of the treatment styles of the different countries covered in the survey. In particular visits to the doctor appear to be much more frequent in the South (almost twice those of the north), while frequency of hospital stays seems larger in the Continental countries. Whereas the age effect is not very clear in doctor visits, it is present very clearly in the data on hospitals.

A consideration of key importance is the immediate economic effect of illness in the sense of the direct costs of treatment to the individual and of the indirect costs his/her treatment would impose. Given that the group is selected to have greater need for medical and health care intervention, one would expect health care expenditure to loom large in the story. Figure 5 examines out of pocket expenses on inpatient care, prescribed drugs and outpatient care for the group who have suffered health deterioration. To facilitate comparison the expenses of the same individuals in the first wave (i.e. before the onset of illness) and the second wave (i.e. after illness struck) are plotted together. The picture emerging is intriguing and complex: In the Nordic countries out of pocket health care expenses were actually larger before the illness, especially for inpatient care, and less so for outpatient care. Only drugs-related expenses are larger after than before the illness. This picture could be consistent with an activation of Welfare State mechanisms designed to protect the ill. If that is so, what we are seeing before the illness is discretionary payments not covered by the social protection system. In Continental states, there is some increase following the illness, which is more marked for the older group. In the South, there is a definite increase for both groups for inpatient care and prescription drugs. Outpatient visits are moving in the opposite directions for the two age groups. In terms of an age gradient there appears to be little relationship in Nordic States, a strong positive link in the Continental states and a weak negative relationship in the south. 
Figure 4a. Number of visits to doctors of those who suffered health deterioration.

$\square$ Number of visits to doctors: persons 50-64 $\square$ Number of visits to doctors: persons 65-80

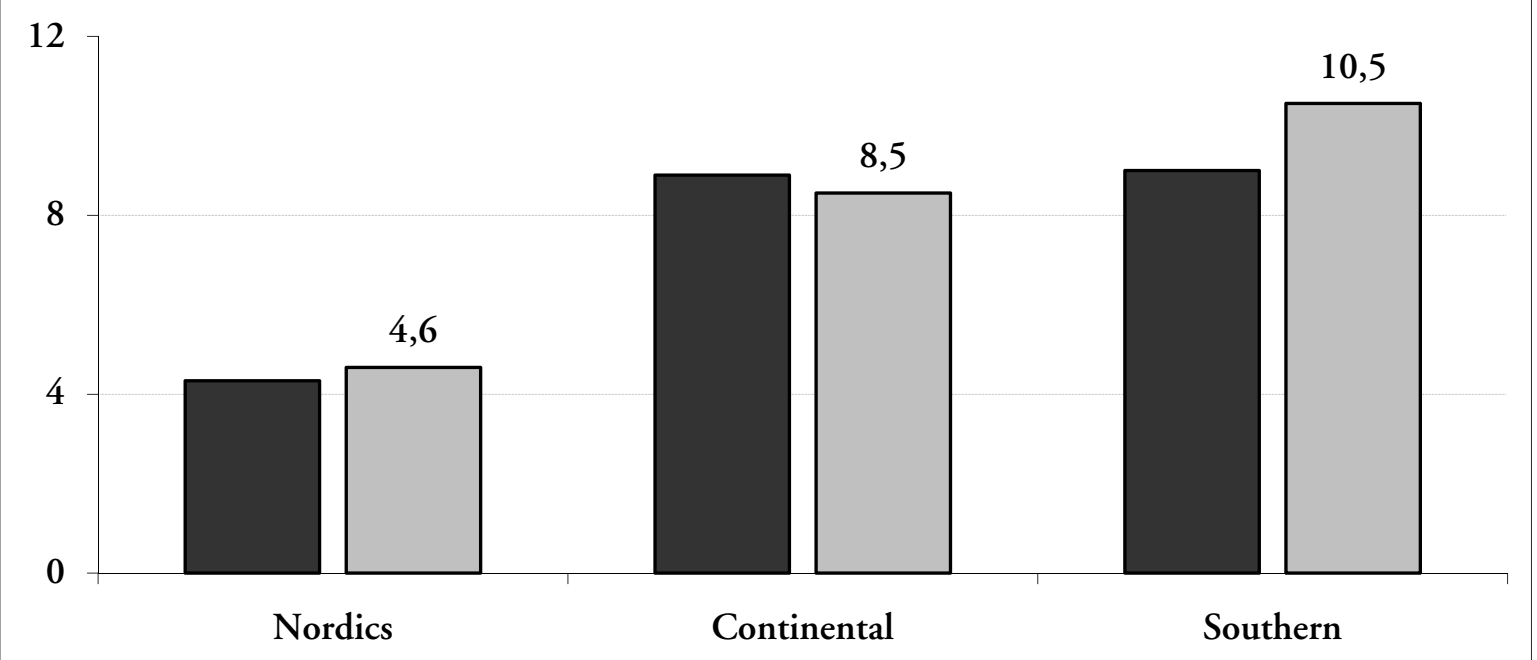

Source: SHARE, wave 1 (2004) and wave 2 (2008)

Figure 4b. (\%) stayed in hospital in the last 12 months of those who suffered health deterioration.

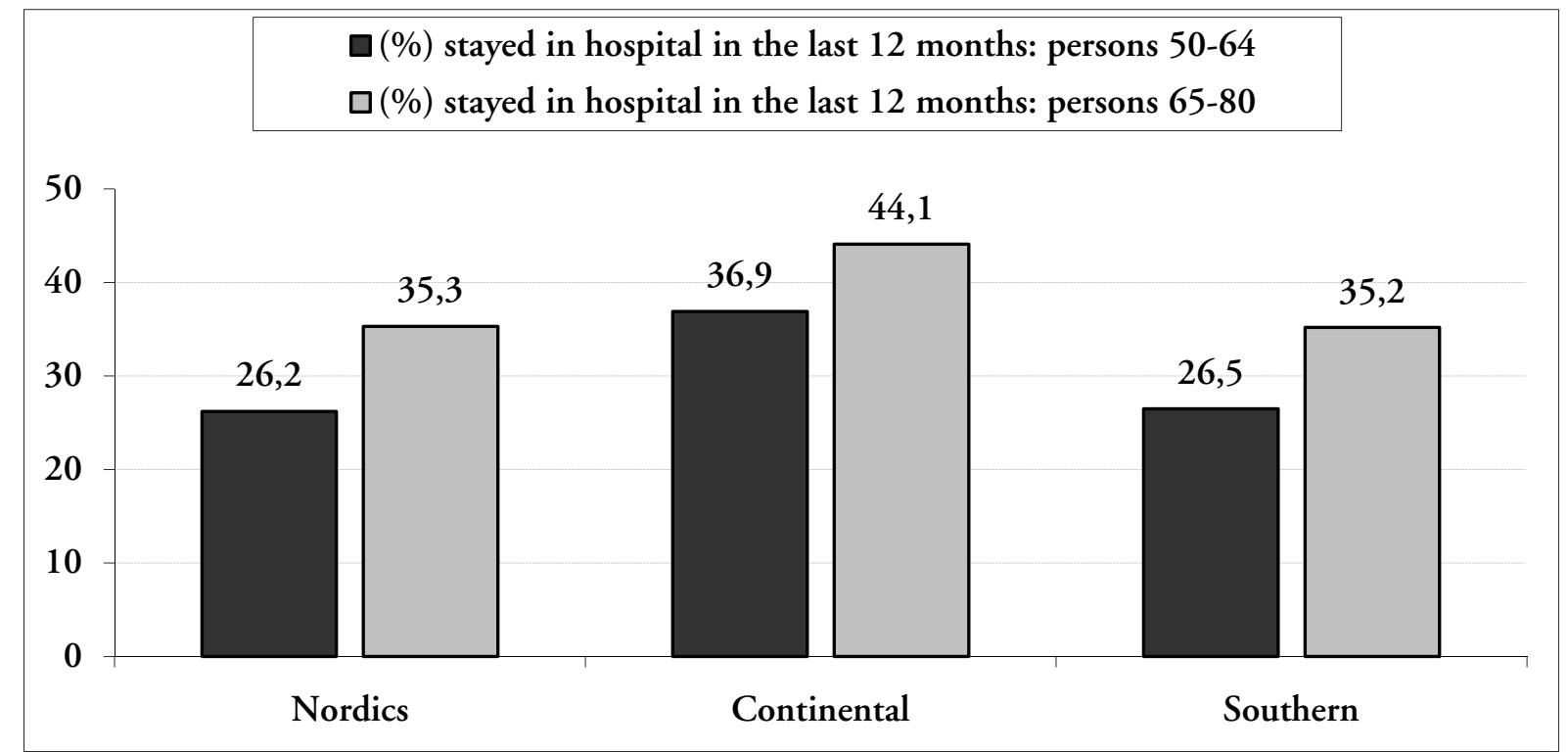

Source: SHARE, wave 1 (2004) and wave 2 (2008). 
Figure 5. Out of pocket expenses (in euros) for the last 12 months.

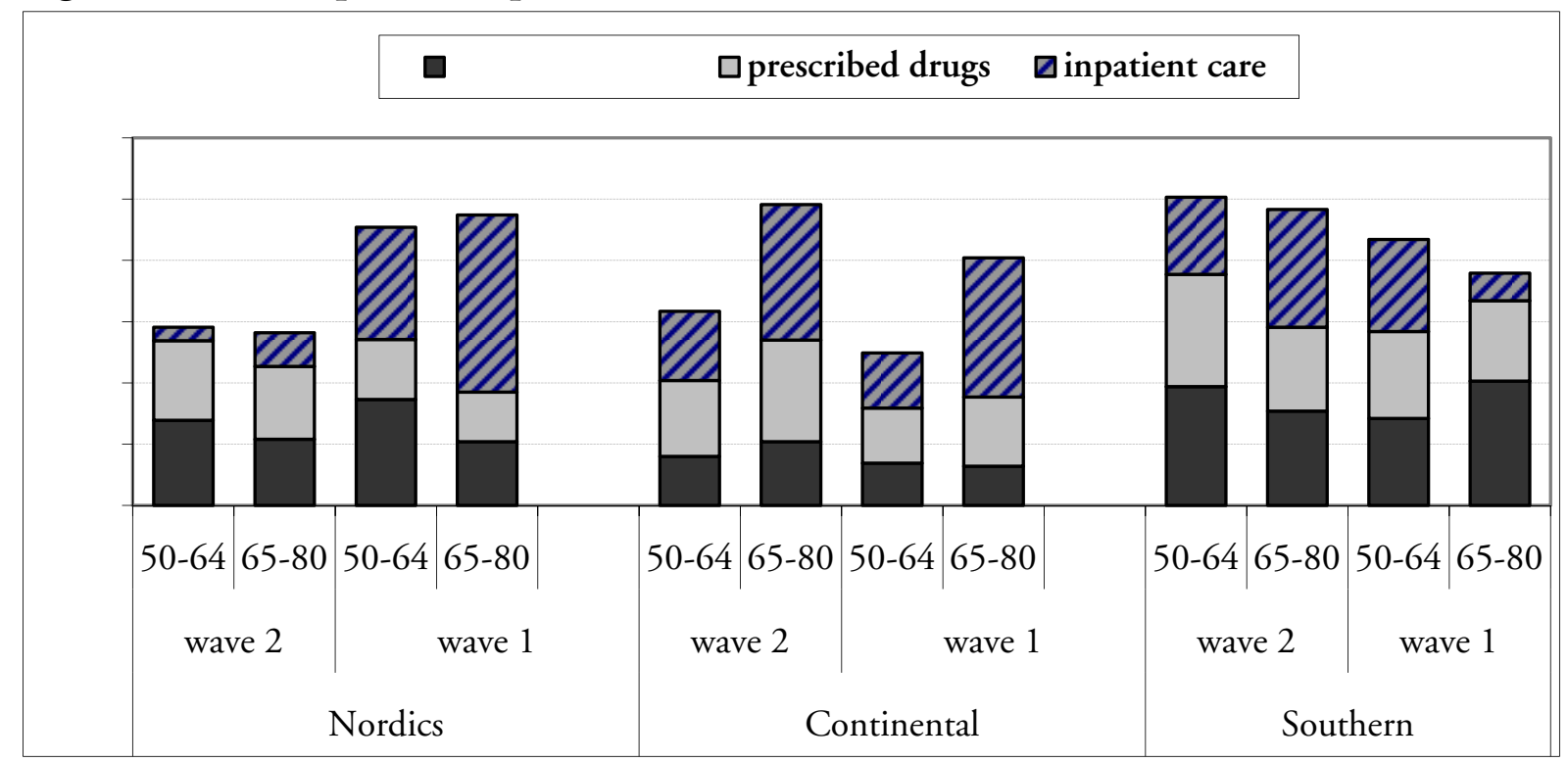

Source: SHARE, wave 1 (2004) and wave 2 (2008).

One surprising fact about the data in Figure 5, given that this is a sample of older individuals selected for having serious health deterioration, is the relative modesty of the average amounts. The maximum average expenditure over a year is EUR 503 (for the younger group in the South). This, of course, disguises considerable variability. Figures $6 \mathrm{a}, 6 \mathrm{~b}$ and $6 \mathrm{c}$ examine the average for non-zero values of expenditure only. We thus see that positive expenses can be much larger, especially in the south. The variability, however, is such that, pre-illness expenses (wave 1) are sometimes higher than those postdating the illness.

Figure 6a. Average non-zero out of pocket expenses (in euros) over the last 12 months for inpatient care (wave 1 and wave 2).

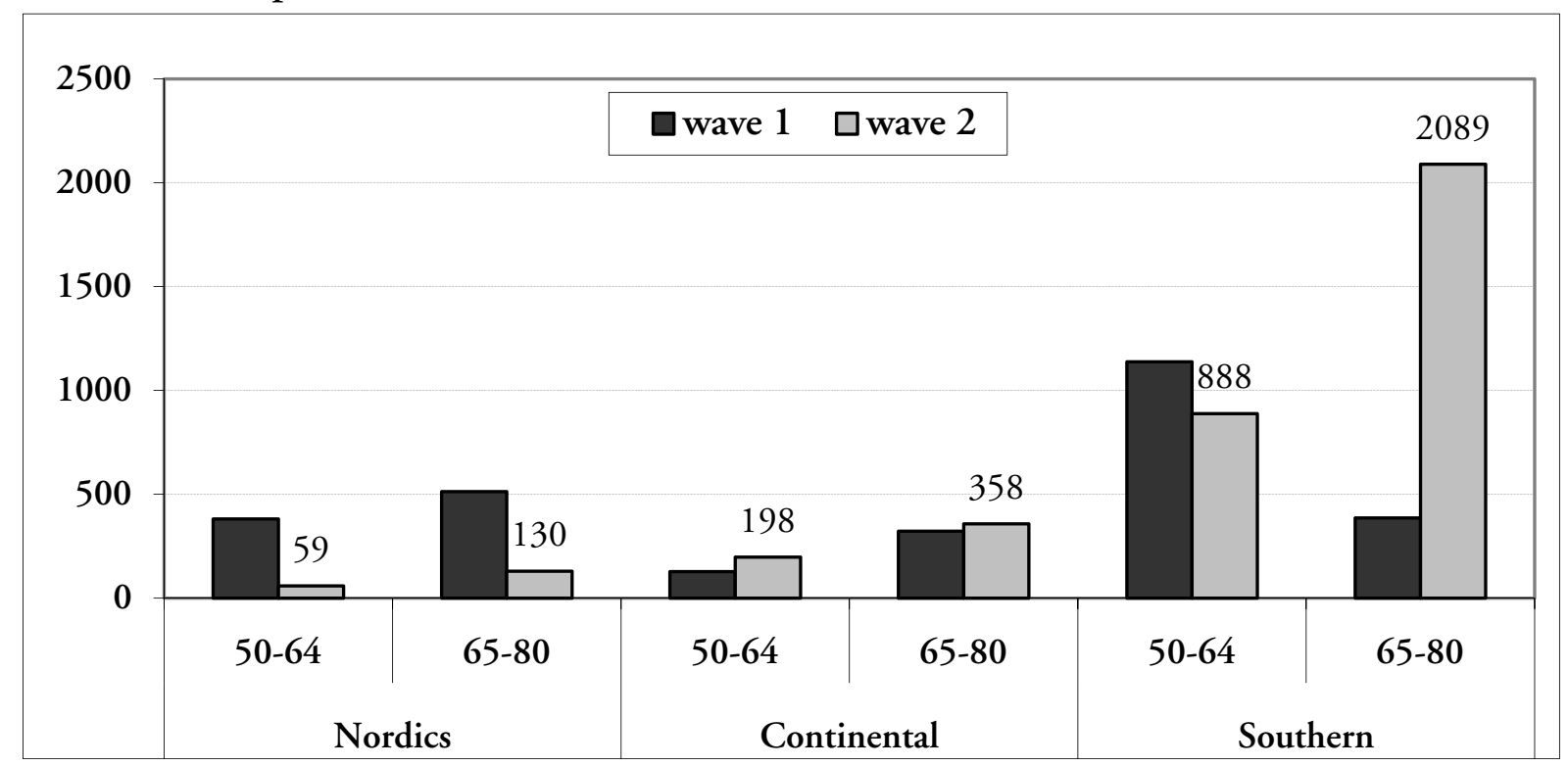

Source: SHARE, wave 1 (2004) and wave 2 (2008). 
Figure 6b. Average non-zero out of pocket expenses (in euros) over the last 12 months for outpatient care (wave 1 and wave 2).

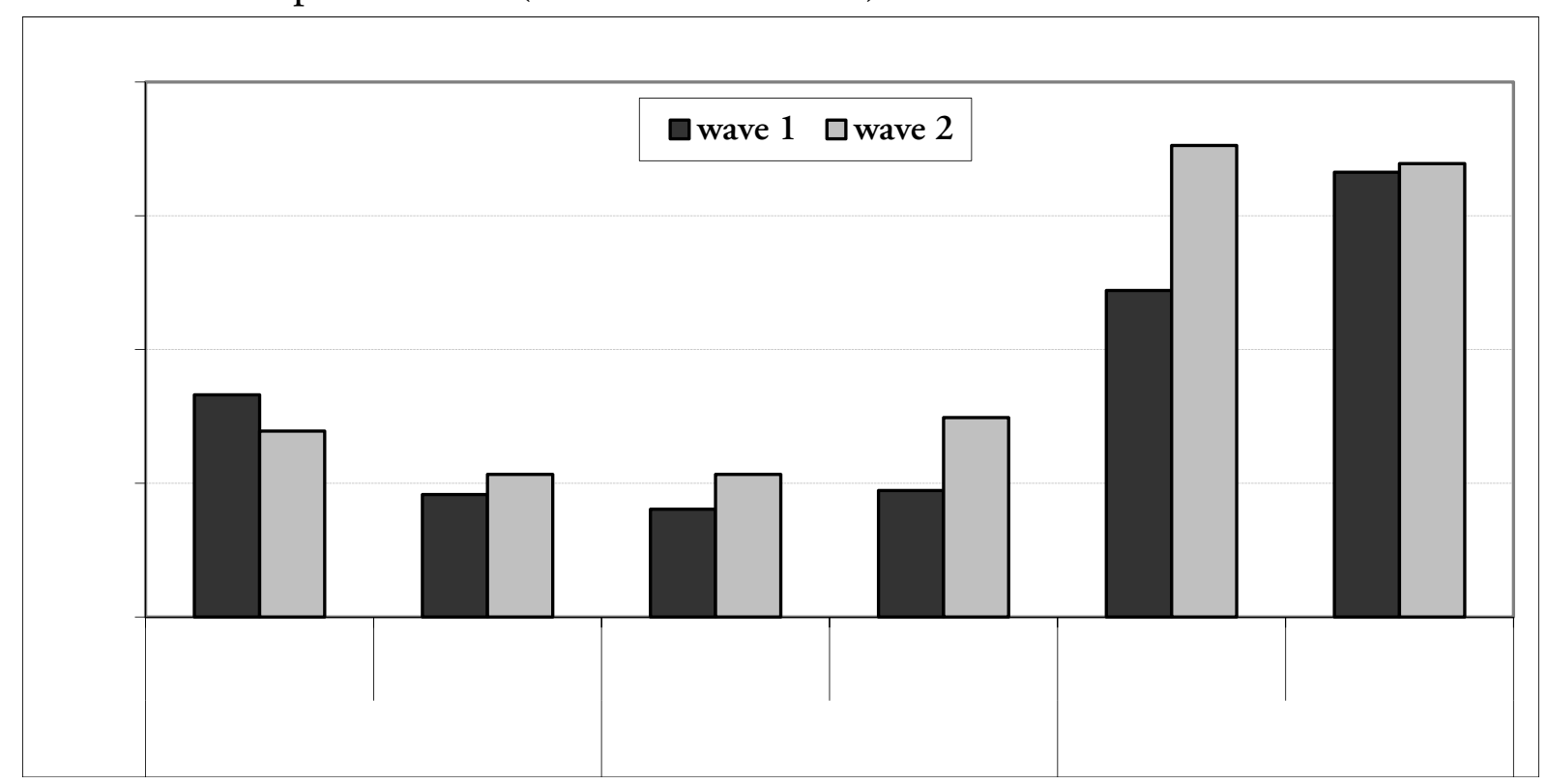

Source: SHARE, wave 1 (2004) and wave 2 (2008).

Figure 6c. Average non-zero out of pocket expenses (in euros) over the last 12 months for prescribed drugs (wave 1 and wave 2).

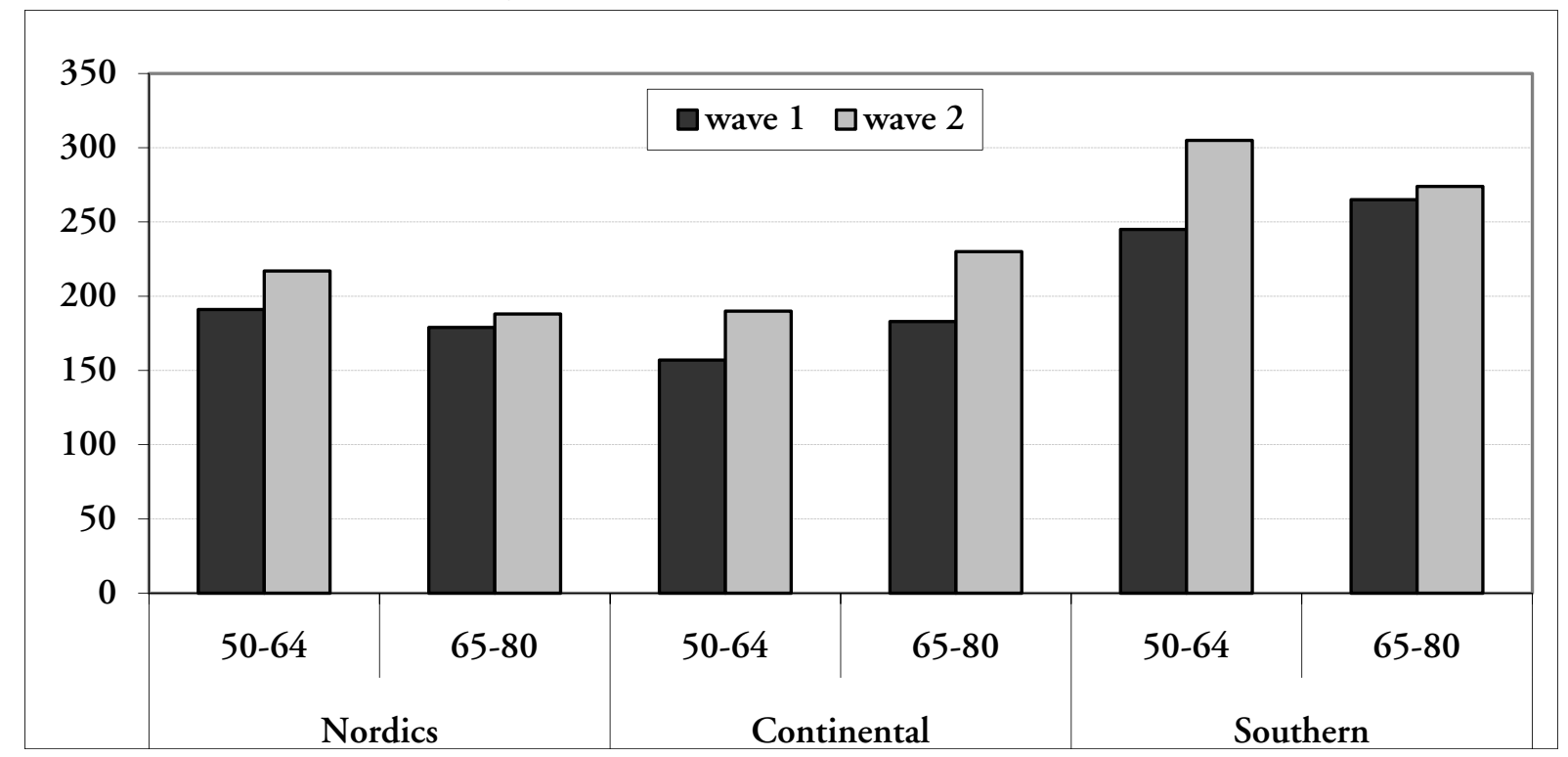

Source: SHARE, wave 1 (2004) and wave 2 (2008).

An important observation (not reported here) is that if one splits the sample further into three income classes, there appears no discernible pattern for extra out-ofpocket expenses for the three country groups.

To approach the question of variability, Table 5 examines above-median expenditure at specific points in the distribution for each category of out-of-pocket expenses. Thus, once we isolate positive expenses, the expenditure in the Nordics is 
Table 5. Distribution of positive total expenditure in Wave 2 (€/year).

\begin{tabular}{lccc}
\hline & Top 50\% & Top 75\% & Top 90\% \\
\hline Nordics & 267 & 402 & 805 \\
Continental & 250 & 610 & 1300 \\
Southern & 250 & 600 & 1250 \\
\hline
\end{tabular}

Source: SHARE, wave 1 (2004) and wave 2 (2008)

$€ 267$, in the South $€ 250$ and in the Continent the same. Rather surprisingly, the distributions for the Continent and the South coincide at the points of 75\% (EUR 600 ) and 90\% (EUR 1250-1300), possibly reflecting open market prices. In the north, amounts at the top end are considerably lower.

The overall impression derived from Figures 5, 6a, 6b, 6c and Table 5 can be summarized as follows:

- In the Nordic states, there is a fall in expenditure when one is ill. Could this be evidence of the operation of the welfare state?

- In the Continental States there is a small but consistent increase, possibly related to copayments.

- In the Southern States: Expenses are both larger and more variable. Could this be evidence of gaps or inequalities in coverage?

\section{Consequences Beyond Health: Employment and Care}

The decision to focus on individuals aged 50+ in the SHARE sample (and in its precursors HRS and ELSA) is justified as allowing us to focus on three groups whose fortunes together comprise the ageing puzzle: A first, younger group, between 50 and 65 who are still actively engaged in the labour market, participation in which is at the very least a live option. At the other extreme are the very old, aged $80+$, for whom health considerations can be expected to be paramount. In between, we find the group who are healthy but have broken links with the labour market and for whom quality of life is most important.

The group who is most likely to be affected by sudden illness is the first group that still involved in the labour market. Illness, in particular is likely to play a part in their decisions to retire or, in general, revise their planning about the timing of retirement. The analysis thus focuses on those who were working in wave 1 of SHARE and have changed their labour market affiliation between the two waves. Figure 7 contrasts transitions out of the labour market of those who have suffered deterioration in health with those who have not. 
Figure 7. Transitions out of employment, those working in Wave 1.

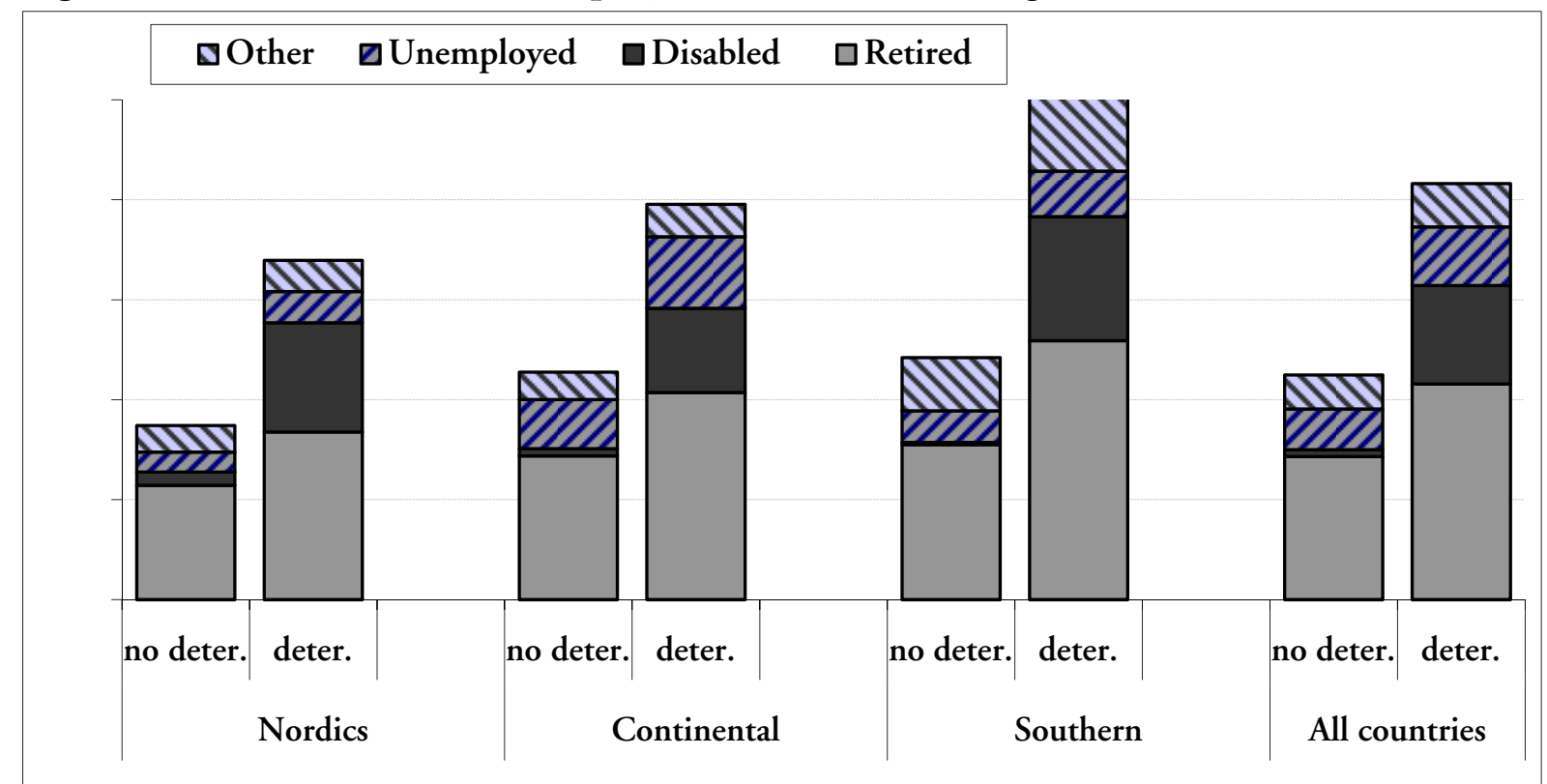

Source: SHARE, wave 1 (2004) and wave 2 (2008).

For people of the ages of the SHARE sample, exit from the labour market is a live option. Figure 7 shows that over $20 \%$ of those working in Wave 1 had exited the labour market. This figure is higher in the South and the Continent, reflecting institutional features of their pension systems. The importance of different pathways to retirement is also evident, with the importance of unemployment in Continental states and of disability pensions in the North (especially in Holland). What figure 7 shows is that health deterioration hastens decisions to exit dramatically. In particular, $42 \%$ of those who suffered deterioration had left the labour market by the second wave; that figure is $50.2 \%$ for the South, $39.6 \%$ in the Continent and $34 \%$ in the North. Also noteworthy is the large percentage (much larger in the South) of those who qualify for an old age pension, which means that people had been working when they had completed the requirements of being awarded an old age pension. (Hence the reason for the larger group in the South is related to low retirement ages). Unemployment as an exit strategy does not play a larger role for health deterioration, a distinction sought (predictably) by disability pensions. Disability pensions are especially important in the North and in the South. Finally, the relatively large 'other' category is composed primarily of women who drop out of the labour market mostly in anticipation of being awarded a pension later on (one would think that a large group may have submitted applications for pensions which must still be pending - a common bureaucratic hurdle in the South).

An important effect (and one that in the US plays a significant role) is the effect of the illness of one spouse on the decision of his/her spouse to retire. ${ }^{12}$ Figure 8

12 See e.g. Munnell and Sass, 2008. 
attempts to look at transitions out of the labour market for working spouses of individuals who suffered health deterioration. As a control, the transitions of working spouses whose partners did not suffer deterioration are also included.

Figure 8 tells an interesting story. The caring-for-an-ill spouse effect appears to exist and to be relatively sizeable in the Nordic (5.1 percentage points difference) and in the continental regions (4.3 percentage points). In the South the difference is large (9.5 percentage points), but is in the 'wrong' direction - spouses of ill individuals are less likely to exit the labour force. Though sample sizes are small, the juxtaposition of North and South gives rise tantalizingly to drawing a conclusion connecting the lack of generosity of the welfare state with the necessity to supplement income to cover the extra expenses of illness.

Figure 8. Transition out of work for working spouses of those who suffered health deterioration.

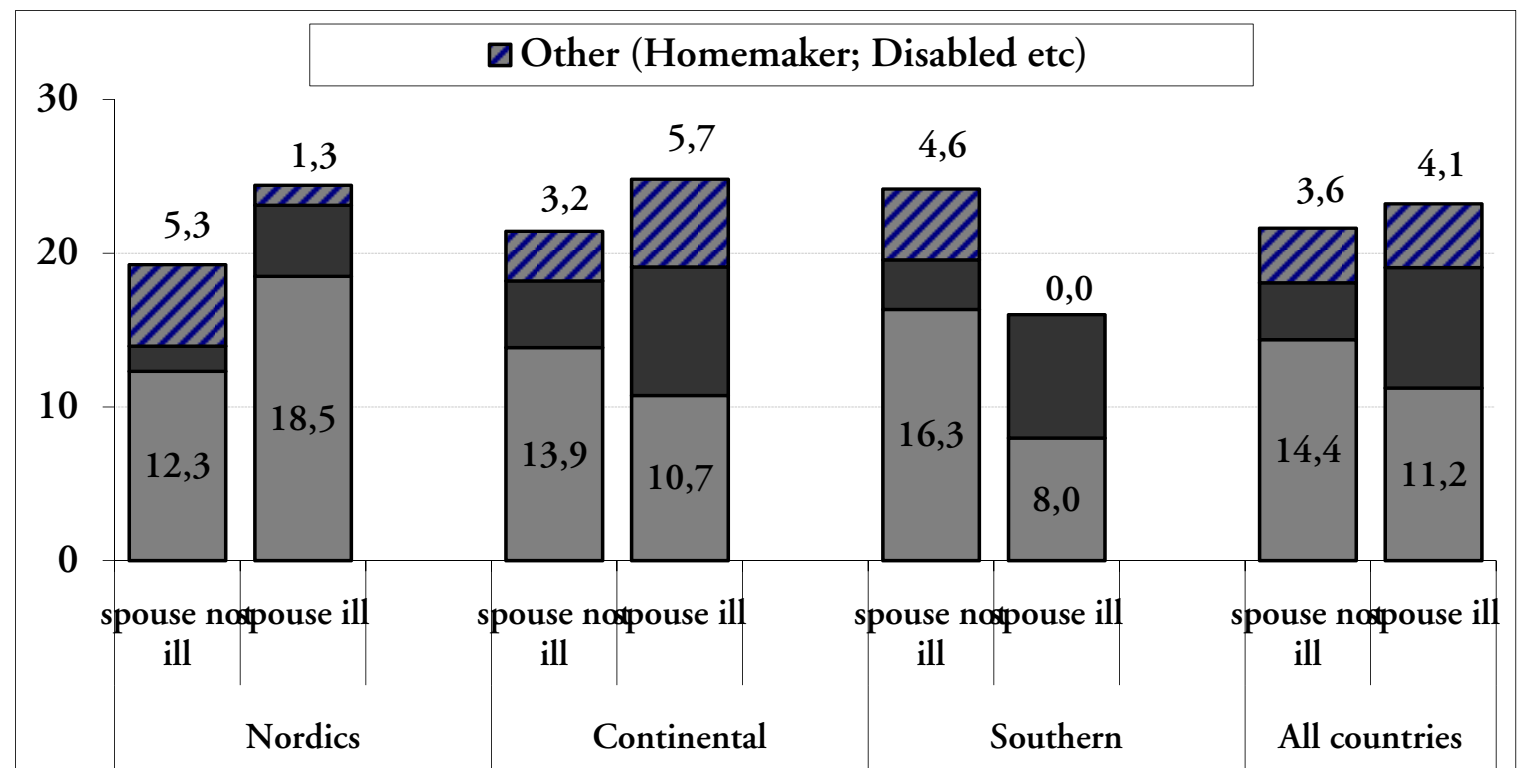

Source: SHARE, wave 1 (2004) and wave 2 (2008).

Of interest in this context of examining exits from the labour market are the reasons for retirement given by the respondents themselves. Table 6 examines the results of a question for which multiple replies were possible. To become eligible for a pension (public or private) is most frequently cited as a self-evident reason - confirming that many retirees interpret and act as if minimum retirement ages were maximum ages. Nevertheless, it is the combination of eligibility and health $(16 \%$ overall, $22.4 \%$ in continental countries, whereas in the South it is actually less than in the healthy group). As an interesting aside, illness causes opposing effects in the North and in the South: in the North fewer exits 'to enjoy life' (22\% healthy vs $10 \%$ deteriorated), whereas in the South it causes more (2.9\% healthy, while $15 \%$ deteriorated). This may reflect differences in philosophical stances on reminders of mortality. 
The last area to be dealt with is that of informal social networks. The onset of sudden and serious illness may be expected to elicit responses in the form of personal care offered to the respondents. SHARE divides help to three types: Personal care -help in bathing, eating dressing etc, Practical care (cooking, shopping, and cleaning) and help with bureaucracy (filling in forms, tax returns, going to the bank, etc). In a sample of ill people of this kind we would expect personal care to loom large and possibly secondarily, practical care. Given this expectations, the results of Table 7 are quite surprising. Personal care is received by only $3 \%$ of under $65 \mathrm{~s}$ and $6.5 \%$ of over $65 \mathrm{~s}$; only in the South does the help given to over-65s come close to $10 \%$. Practical care is more important, though it never rises above a quarter of the sample. This picture of small importance of care offered is consistent with most care being provided within the household - most commonly by the spouse. In such situations, the mobilization of care within the household would obviate the need for outside help.

Table 6. Reasons given for retirement for those who retired between the two waves.

\begin{tabular}{|c|c|c|c|c|c|c|c|c|}
\hline \multirow[b]{2}{*}{$\begin{array}{l}\text { Reason for retire- } \\
\text { ment }\end{array}$} & \multicolumn{2}{|c|}{ All countries } & \multicolumn{2}{|c|}{ Nordics } & \multicolumn{2}{|c|}{ Continental } & \multicolumn{2}{|c|}{ Southern } \\
\hline & $\begin{array}{c}\text { no } \\
\text { deter. }\end{array}$ & deter. & $\begin{array}{c}\text { no } \\
\text { deter. }\end{array}$ & deter. & $\begin{array}{c}\text { no } \\
\text { deter. }\end{array}$ & deter. & $\begin{array}{c}\text { no } \\
\text { deter. }\end{array}$ & deter. \\
\hline $\begin{array}{l}\text { Became eligible for } \\
\text { public pension }\end{array}$ & 48.7 & 63.5 & 33.3 & 44.7 & 45.5 & 63.0 & 61.1 & 71.1 \\
\hline $\begin{array}{l}\text { Became eligible for } \\
\text { other kind of } \\
\text { pension }\end{array}$ & 21.0 & 18.2 & 20.8 & 50.7 & 21.6 & 7.7 & 19.7 & 26.0 \\
\hline $\begin{array}{l}\text { Was offered an early } \\
\text { retirement option }\end{array}$ & 19.6 & 8.0 & 31.0 & 21.8 & 23.3 & 6 & 7.7 & 5.7 \\
\hline Made redundant & 3.8 & 3.1 & 8.7 & 10.5 & 2.8 & 3.3 & 4.2 & 0.0 \\
\hline Ill health & 7.5 & 16.0 & 5.2 & 10.1 & 8.3 & 22.4 & 6.6 & 6.1 \\
\hline Family reasons & 8.9 & 4.9 & 14.9 & 7.9 & 10.9 & 6.9 & 2.6 & 0.0 \\
\hline To enjoy life & 8.6 & 9.5 & 22.1 & 9.6 & 8.9 & 6.5 & 2.9 & 15.1 \\
\hline
\end{tabular}

Source: SHARE, wave 1 (2004) and wave 2 (2008).

Given the indicative findings of Table 7 the disturbing possibility emerges of a, possibly serious, gap in care. Care may be provided by informal help from outside the household, or by professional carers. Equally, though care may be provided by a member of the family - the spouse or, in the case of cohabitation with other generations a child. In the last type of care, physical proximity (residence in the same household or the same building) acquires greater importance. Table 8 attempts to approach this complex question. 
Table 7. Types of help provided to those whose health deterioration.

\begin{tabular}{lcccccccc}
\hline \multirow{2}{*}{$\begin{array}{l}\text { Country } \\
\text { groups }\end{array}$} & \multicolumn{2}{c}{ Personal care } & \multicolumn{2}{c}{ Practical care } & \multicolumn{2}{c}{$\begin{array}{c}\text { Help with } \\
\text { bureaucracy }\end{array}$} & \multicolumn{2}{c}{$\begin{array}{c}\text { Any type of } \\
\text { help received }\end{array}$} \\
\cline { 2 - 9 } & $\mathbf{5 0 - 6 4}$ & $\mathbf{6 5 - 8 0}$ & $\mathbf{5 0 - 6 4}$ & $\mathbf{6 5 - 8 0}$ & $\mathbf{5 0 - 6 4}$ & $\mathbf{6 5 - 8 0}$ & $50-64$ & $\mathbf{6 5 +}$ \\
\hline Nordics & 2.6 & 2.0 & 27.8 & 21.7 & 6.0 & 6.4 & 33.2 & 26.1 \\
Continental & 2.4 & 4.7 & 22.9 & 27.1 & 2.0 & 9.0 & 24.3 & 31.4 \\
Southern & 3.9 & 9.5 & 6.4 & 19.1 & 7.0 & 17.3 & 13.5 & 26.5 \\
All & 2.9 & 6.5 & 18.0 & 23.3 & 4.1 & 12.3 & 21.8 & 28.9 \\
\hline
\end{tabular}

Source: SHARE, wave 1 (2004) and wave 2 (2008).

Table 8 disaggregates the sample by age and looks at all kinds of help that can be identified by the questionnaire: daily help, coresidence of a family member and a combination of both. Co-residence bears the brunt of care offered, as one could expect, even in the Northern Countries. Even so, there remains a large percentage, which is growing with age, of people who receive neither type of care $(16 \%$ in the younger group, $24 \%$ in the older). The percentage is especially large among the older group in the North (39\%), and is below one in ten only for the younger group in the South.

Table 8. Gaps in care? Help daily (A), Coresidence (B) and their absence.

\begin{tabular}{lcccccccc}
\hline \multirow{2}{*}{$\begin{array}{l}\text { Country } \\
\text { Groups }\end{array}$} & \multicolumn{4}{c}{ Persons aged 50-64 } & \multicolumn{4}{c}{ Persons aged 65-80 } \\
\cline { 2 - 9 } & A and & Only & Only & Neither & A and & \multirow{2}{*}{ Only A } & Only B & $\begin{array}{c}\text { Neither } \\
\text { A nor B }\end{array}$ \\
\hline Nordics & 1,0 & 1,8 & 69,4 & 27,9 & 1,2 & 2,2 & 58,0 & 38,6 \\
Continental & 3,0 & 0,1 & 79,2 & 17,7 & 3,0 & 2,9 & 72,1 & 22,0 \\
Southern & 2,0 & 1,1 & 88,2 & 8,7 & 6,2 & 4,3 & 67,2 & 22,3 \\
All countries & 2,4 & 0,6 & 81,1 & 15,9 & 4,2 & 3,4 & 68,8 & 23,5 \\
\hline
\end{tabular}

Source: SHARE, wave 1 (2004) and wave 2 (2008).

This incomplete, yet sobering, finding of the possibility of major gaps or at the very least serious lags in social response, is possibly a fitting place to stop this impressionistic analysis of the social responses to the onset of illness. Despite the spread of the Welfare State there appear to be large numbers of older citizens who apparently cope with a serious illness on their own.

\section{Conclusions -the Way Forward}

This paper identified cases of immediate and serious need that affected a random sample of older European citizens between 2004 and 2006/7. Using only simple tabulations and descriptive statistics we attempted a 'naked eye' overview of how 
the social and economic effects of illness played out in 11 European countries categorized (for reasons of sample economy) into three broad regions with comparable social protection systems. The analysis tried to uncover relationships by disaggregating according to gender and age. In doing so we have reached a number of conclusions:

- The prevalence of health deterioration was roughly uniform across countries. Women in the South could be said to be more prone, but due to 'generalised malaise', rather than to an identified illness

- Health deterioration produced major effects on the ability to function in everyday living. This effect increases with age, while women appear to feel effects more keenly.

- The effect on mental health and the tendency to depression is important. Men's health impact rises sharply with age, while women are more stoic and appear to accept deterioration as a natural part of ageing.

- Treatment styles are very different across Europe. More hospitals in Continental States, whereas Doctor visits are more common in the South.

- Out of pocket Expenses on average are not particularly high. But there exist instances of considerable expenses in all areas. In the North there is evidence supporting the efficacy of the Welfare state in reducing expenses for the sick. In the Continent the picture is consistent with copayments, whereas in the South gaps in coverage must be part of the story.

- Health deterioration is instrumental in all cases in driving individuals out of employment, especially in the South.

- Health deterioration appears to have an effect of the decision of the spouse to retire. In the South, the spouse remains in the labour market, possibly to compensate for loss of earnings. In the North, on the contrary, spouses leave the labour market, presumably to look after their sick partners.

- Finally, there appears to be some evidence of large gaps in Care offered to sick.

- This explorative naked- eye examination of the data has already yielded a good deal of food for thought, Even in the relatively short time span between the two waves of SHARE, some tantalizing effects, as well as disparities between behaviour in the North, the centre and the South of Europe are beginning to emerge.

- This picture can be complemented, as a second step by looking at effects on income and, most importantly, in running down assets as a response to illness. However, this kind of complex effect is unlikely to be discernible in the simple analysis of this paper. A diagrammatic analysis is essentially an analysis of limited dimensionality employing reduced forms. Complex effects are much more likely to be reflected in partial coefficients of fully specified 
multivariate models. Though in those kind of models there is greater chance of discerning effects, the immediacy of direct observation is lost. Nevertheless, and regardless of the merits of a 'naked eye' approach, the next steps must be to exploit in a more thorough manner the panel nature of the data and thus to extract more and better defined information from the same data.

- Returning to the original theme of the paper, the mobilization of social resources following illness, the direct evidence from SHARE lends some early support to a hypothesis that social systems play a significant role in guiding responses to a social and family emergency. The differences that were almost a constant accompaniment of the naked eye analysis, are consistent with being - at least partly - the reflections of social policy choices. How much, and to what extent must await a fuller investigation employing sophisticated econometric tools, and/or later waves of SHARE where the passage of time would have had the effect of increasing the sample size.

Antigone Lyberaki is Professor of Economics at the Department of Economics and Regional Development at Panteion University, Athens, Greece. Platon Tinios is an economist, Assistant Professor at the Department of Statistics and Insurance Science at the University of Piraeus, Greece.

\section{Acknowledgement}

Warm thanks are due to Thomas Georgiadis for irreplaceable assistance with this paper. 


\section{References}

Alber, J., "The European Social Model and the United States," European Union Politics 7:3 (2006), 393-419.

Attias-Donfut, C., Ogg, J. and Wolff, F.C., "Family Support", pp. 171-178 in Borsch-Supan et al. (eds.) Health, Ageing and Retirements in Europe, first results from SHARE, MEA Publication, 2005.

Avendano, M. and Mackenbach, J., "Changes in Physical Health Among Older Europeans", pp. 116-122 in A. Börsch-Supan, A. Brugiavini, H. Jurges, A. Kapteyn, J. Mackenbach, J. Siegrist and G. Weber (eds) Health Ageing and Retirement in Europe (2004-2007): Starting the Longitudinal Dimension. Mannheim, 2008.

Bettio, F. and Plantenga, J., "Comparing Care Regimes in Europe," Feminist Economics, 10:1 (2004), 85-113

Boeri, T., "Let Social Policy Models Compete and Europe Will Win", Paper presented at a Conference hosted by the Kennedy School of Government, Harvard University, 11-12 April, 2002.

Börsch-Supan, A. and Jürges, H. (eds.), The survey of Health, Ageing and Retirement in Europe-Methodology. Mannheim: Mannheim Research Institute for the Economics of Aging (MEA), 2005.

Börsch-Supan, A. Brugiavini, A., Jürges, H., Kapteyn, A., Mackenbach, J. Siegrist J.and Weber, G. (eds.), Health Ageing and Retirement in Europe (2004-2007): Starting the Longitudinal Dimension. Mannheim, 2008.

Börsch-Supan, A., Brugiavini, A., Jürges, H., Mackenbach, J., Siegrist, J. and Weber, G. (eds), Health, Ageing and Retirement in Europe - First Results from the Survey of Health, Ageing and Retirement in Europe, MEA: Mannheim, 2005.

Brugiavini, A., Croda, E. and Mariuzzo, F., "Labour Force Participation of the Elderly: Unused Capacity?”, pp. 236-240 in Borsch-Supan et al. (eds.) Health, Ageing and Retirement in Europe: First Results from the Survey of Health, Ageing and Retirement in Europe, MEA Publication, 2005.

Commission of the European Communities, Joint Report by the Commission and Council on Social Inclusion. Directorate of Employment and Social Affairs, 2002.

Dewey, M.E. and Prince, M.J., "Mental health" pp. 108-117 in Börsch-Supan, et al., Health, Ageing and Retirement in Europe: First Results from the Survey of Health, Ageing and Retirement in Europe, MEA Publication, 2005.

Esping-Andersen G. (eds.), The Three Worlds of Welfare Capitalism, Polity Press, 1990.

Esping-Andersen G. (eds.), Welfare States in Transition: National Adaptations in Global Economies, London, Sage, 1996. 
Ferrera, M., "The Southern Model of Welfare State in Social Europe", Journal of European Social Policy, 6:1 (1996), 17-37.

Kohli, M. Kunemund, H. and J. Ludicke, "Family structure, proximity and contact”, pp. 41-47, in Borsch-Supan et al. (eds.) Health, Ageing and Retirement in Europe: First Results from the Survey of Health, Ageing and Retirement in Europe, MEA Publication, 2005.

Mackenbach, J., Avendano, M., Andersen-Ranberg, K. and Aro, A., "Physical Health", pp. 82-88 in in Borsch-Supan et al. (eds.) Health, Ageing and Retirement in Europe: First Results from the Survey of Health, Ageing and Retirement in Europe, MEA Publication, 2005.

Meijer, E., Zamarro, G. and Fernades, M., "Overview of Available Aging Data Sets” pp. 24-29 in A. Börsch-Supan, A. Brugiavini, H. Jurges, A. Kapteyn, J. Mackenbach, J. Siegrist and G. Weber (eds.) Health Ageing and Retirement in Europe (2004-2007): Starting the Longitudinal Dimension. Mannheim, 2008.

Munnel, A.H. and S.A.Sass, Working Longer. The Solution to the Retirement Income Challenge, The Brookings Institution, Washington D.C., 2008.

Nicholas, S. Huppert, F.A., McWilliams, B. and Melzer, D., "Physical and Cognitive Function" pp. 249-271 in Health, wealth and lifestyles of the older population in England: The 2002 English Longitudinal Study of Ageing, (ed.) M Marmot, J. Banks, R. Blundell, C. Lessof and J. Nazroo,. London: IFS, 2003.

Prince, M.J., Reischies, F., Beekam, A.T.F., Fuhrer, R., Jonker, C., Kivela, S.L., Lawlor, B.A., Lobo, A., Magnusson, H., Fichter, M., Van Oyen, H., Roelands, M., Skoog, I., Turrina, C., Copeland, J.R.M., "Development of the EURO-D scale: a European Union initiative to compare symptoms of depression in 14 European centres," British Journal of Psychiatry, 174 (1999a), 330338.

Prince, M.J., Reischies, F., Beekam, A.T.F., Fuhrer, R., Jonker, C., Kivela, S.L., Lawlor, B.A., Lobo, A., Magnusson, H., Fichter, M., Van Oyen, H., Roelands, M., Skoog, I., Turrina, C., Copeland, J.R.M., "Depression symptoms in late life assessed using the EURO-D scale," British Journal of Psychiatry, 174 (1999b), 339-345.

Reher, D.S., "Family Ties in Western Europe: Persistent Contrasts," Population and Development Review, 24:2 (1998), 203-234.

Sapir A., Globalisation and the Reform of the European Social Models, background document for ECOFIN, Manchester, 9 September, 2005. 


\section{Appendix}

Table A1. Distribution of time gaps between w1 and w2 interview.

\begin{tabular}{|c|c|c|c|c|}
\hline \multirow{2}{*}{ Country } & \multicolumn{4}{|c|}{ Difference between $w 1$ and $w 2$ in months } \\
\hline & $25 \%$ & Median & $75 \%$ & Mean \\
\hline SE & 26 & 28 & 30 & 28.2 \\
\hline $\mathrm{DK}$ & 29 & 30 & 32 & 30.6 \\
\hline NL & 31 & 32 & 33 & 31.9 \\
\hline $\mathrm{DE}$ & 29 & 30 & 32 & 30.5 \\
\hline $\mathrm{BE}$ & 19 & 21 & 24 & 21.3 \\
\hline FR & 17 & 25 & 26 & 22.4 \\
\hline AT & 29 & 30 & 32 & 30.5 \\
\hline $\mathrm{CH}$ & 29 & 30 & 31 & 30.1 \\
\hline ES & 29 & 30 & 32 & 30.4 \\
\hline IT & 29 & 31 & 32 & 30.5 \\
\hline GR & 27 & 33 & 34 & 30.1 \\
\hline \multicolumn{5}{|c|}{ Longitudinal sample } \\
\hline Country group & $25 \%$ & Median & $75 \%$ & Mean \\
\hline Nordics & 28 & 30 & 32 & 30.0 \\
\hline Continental & 21 & 26 & 30 & 25.4 \\
\hline Southern & 29 & 31 & 33 & 30.7 \\
\hline \multicolumn{5}{|c|}{ Persons with no health deterioration (as defined in the analysis) } \\
\hline Country group & $25 \%$ & Median & $75 \%$ & Mean \\
\hline Nordics & 28 & 30 & 32 & 30.1 \\
\hline Continental & 21 & 26 & 30 & 25.4 \\
\hline Southern & 29 & 31 & 33 & 30.8 \\
\hline \multicolumn{5}{|c|}{ Persons with health deterioration (as defined in the analysis) } \\
\hline Country group & $25 \%$ & Median & $75 \%$ & Mean \\
\hline Nordics & 28 & 30 & 32 & 29.8 \\
\hline Continental & 21 & 26 & 30 & 25.6 \\
\hline Southern & 29 & 31 & 32 & 30.6 \\
\hline
\end{tabular}

Source: SHARE, wave 1 (2004) and wave 2 (2008). 